\title{
Plating: A Rational Option for Mid Shaft Clavicle Fractures
}

\author{
Harindra Himanshu ${ }^{1}$, Mani Bhushan Prasad ${ }^{2}$, Ajay Kumar Verma $^{3}$, \\ Lal Bahadur Manjhi ${ }^{4}$ \\ ${ }^{I}$ Senior Resident, ${ }^{2}$ Assistant Professor, ${ }^{3}$ Assistant Professor, ${ }^{4}$ Associate Professor\& Head \\ Department Of Orthopaedics, RIMS, Ranchi -834009, Jharkhand, India.
}

\begin{abstract}
Fractures of clavicle is one of the most common injuries of human skeleton. It has been traditionally treated non-operatively but the recent trend is shifting towards internal fixation because of the high complication rates and poor functional outcome with cosmetic deformity. The present study is undertaken to study the role of surgical management and assess its functional outcome in fresh displaced mid shaft clavicle fractures from August 2013 to July 2015. A total of 40 patients with displaced mid shaft clavicle fractures were included in the study. Patients were between the age group of 19 to 55 years with 30 male and 10 females. Fractures were classified according to Robinson's classification. Functional Outcome was evaluated according to the 100-point scoring system of CONSTANT AND MURLEY. Excellent results were noted in 75\%, good for $20 \%$, fair for 5\%. We encourage plating as a one of the method of fixation of clavicle fractures, because stable fixation in middle third clavicle fractures performed carefully is safe and effective treatment method to gives immediate pain relief and restore normal shoulder function with minimal complication.
\end{abstract}

Keywords: clavicle fractures, human skeleton, internal fixation, constant and murley

\section{Introduction}

Clavicle fractures are common injuries in young, active individuals, and they account for approximately $2.6 \%$ of all fractures ${ }^{1}$ and $44 \%$ of all injuries to the shoulder girdle ${ }^{2}$. The majority of clavicular fractures ( $80 \%$ to $85 \%$ ) occurs in the midshaft ${ }^{1}$ and over half of these fractures are displaced ${ }^{3}$. Distal third fractures are the next most common type and account for approximately ( $15 \%$ to $20 \%$ ) of all the clavicle fractures ${ }^{1}$. Medial third fractures are the rarest and accounts for $5 \%$, perhaps because of the difficulty in accurately imaging (and identifying) them ${ }^{4,5}$. The most common reported mechanism of injury that produces a midshaft fracture of the clavicle, is a direct blow on the point of the shoulder ${ }^{6,7}$. Robinson ${ }^{6}$ reported in an epidemiologic study that the annual incidence in males was highest in the under-20 age group, decreasing with each subsequent age cohort. The incidence in females was more constant, with peaks seen in teenagers (e.g., sports, motor vehicle accidents) and the elderly (e.g., osteoporotic fractures from simple falls).Various older studies suggested that a fracture of the shaft of the clavicle, even when significantly displaced, was an essentially benign injury with an inherently good prognosis when treated nonoperatively ${ }^{1}$. This thinking dominated the approach to clavicle fractures for decades, but recently, there has been increasing evidence that the outcome of nonoperatively treated (especially displaced or shortened) midshaft fractures is not as optimal as was once thought. In 1997, Hill et al. ${ }^{8}$ were the first to use patient-oriented outcome measures to examine 66 consecutive patients with displaced midshaft clavicle fractures, and they found an unsatisfactory outcome in $31 \%$, as well as a nonunion rate of $15 \%$. In a meta analysis of the literature from 1975 to 2005 , Zlowodzki et al. ${ }^{9}$ presented a systemic review encompassing 2144 fractures and found that the nonunion rate for nonoperatively treated displaced midshaft clavicle fractures was $15.1 \%$, exponentially higher than that previously described . Zlowodzki et al.'s ${ }^{9}$ meta analysis showed a relative risk reduction of $86 \%$ (from $15.1 \%$ to $2.2 \%$ ) for nonunion with primary plate fixation compared with nonoperative treatment . However, recent studies have found higher rates of shoulder pain, shoulder weakness, residual pain ${ }^{10}$, symptomatic malunion, nonunion, and poor functional outcome with cosmetic deformity ${ }^{3}$ with non-operative treatment .So, the recent trend is shifting towards internal fixation of these displaced midshaft clavicle fractures (DMCF) ${ }^{3}$.A variety of surgical techniques have been described for the treatment of displaced MSCFs. Operative treatment of displaced MSCFs can be achieved successfully using plates or intramedullary (IM) implants like Rush pins, Kirschner wires ${ }^{11}$ knowles-pin fixation, and elastic intramedullary nailing ${ }^{12}$.

\section{Aims And Objectives}

This study is intended to evaluate the outcome of fixation of mid shaft clavicular fracture using plates at our institute with respect to -

1. Stability at fracture site.

2. Functional outcome.

3. Complications of surgery 


\section{Materials And Methods}

The study was carried out in patients treated for closed displaced mid shaft clavicle fractures from August 2013 to July 2015. A total of 42 patients with closed displaced midshaft clavicular fractures were admitted. Out of these 42 patients, 40 were treated surgically and included in the study.

\section{Inclusion Criteria}

1. Age between 19 to 55 years

2. Duration $<2$ weeks .

3. Shortening of over $15 \mathrm{~mm}$

4. Axial malalignment of over $30^{\circ}$ with no cortical bone contact

\section{Exclusion Criteria}

1. Clavicle fractures in Polytrauma patients

2. Open fractures

3. Pathological fractures.

4. Active skin lesion \& infection at operative site .

5. Patients neurologically unstable (Glasgow Coma Scale $<12$ )

6. Medical contraindication to surgery or anaesthesia.

7. Patients with pre-existent morbidity concerning arm, shoulder or hand.

8. Fractures of $>2$ weeks duration.

9. Bilateral clavicle fractures.

10. Segmental fracture.

11. Fractures with associated neurovascular injury.

\section{Technique}

Surgery was performed under general anaesthesia. They were positioned in a "beach-chair semi sitting" position with a folded towel under the affected shoulder. The c- arm and its monitor were placed in front of the surgeon on the opposite side of the operating table. An oblique skin incision was made centered superiorly over the fracture site. Supra clavicular nerves were identified and spared wherever possible, keeping soft tissue dissection to a minimum. The subcutaneous tissue and platysma muscle are kept together as one layer .After reduction of fractures, plate was fixed on the superior surface of the bone, starting medially using bicortical screws. In oblique or complex fractures, inter fragmentary lag screws were used. The fascia and skin were closed in layers. None of the cases had primary bone grafting.

\section{Postoperative Mobilization \& Rehabilitation}

$>$ Day 1 : Arm was placed in a standard sling for comfort with active finger movements.

$>$ Day 2 : Patients were discharged with standard sling in situ .

$>$ Day 3 : Early shoulder mobilization, starting with gentle pendulum exercises .

$>$ Day 7 : Active range of movement exercises but overhead shoulder abduction not allowed .

$>$ Day 14 : Sutures removed and radiographs were taken.The sling is discontinued, and unrestricted rangeof-motion exercises were allowed, but strengthening, resisted exercises or sporting activities were not allowed.

\section{Follow Up Protocol}

All patients were followed for at least six months . The follow up visits were done at: 1,3,6,12,18 months . On every visit, clinical evaluation was done according to the 100-point scoring system of Constant and Murley ${ }^{13}$ and radiologically by X-ray. Radiologically the presence of callus, and complications were seen. It is generally advised that contact (football, hockey) and/or unpredictable (mountain biking, snowboarding) sports be avoided for 12 weeks postoperatively.

\section{Observation And Results}

The Study involved 40 patients of clavicle fractures, which were operated in Orthopeadic department in our hospital. The age distribution of patients ranges from $19-55$ years. The average age was 32 yrs. Youngest was 19 while oldest was 55 years. $60 \%$ patients were in age group of $19-39$ yrs. The Study involved $30(75 \%)$ males and $10(25 \%)$ females. Left Side was involve in 6 (15\%) and right in $34(85 \%)$. Mode of injury is direct blow on the shoulder in $34(85 \%)$ and indirect in $6(15 \%)$ patients. Indirect injury occurred due to fall on out stretched hand but in direct injury the most common mode was road traffic accidents (fall from two wheelers, auto etc ) in 26 ( $65 \%$ ), and fall from height due to slipping in 8 ( $20 \%$ ) patients . Plain radiograph of clavicle with shoulder is taken in AP view to assess the site ,type and geometry ( ie : 
displacement, angulation and communition ) of fracture . Type -2 middle third clavicle fracture type - Type 2 B -1 ( displaced with simple or single butterfly fragment) occurred in 34 patients and Type 2 B -2 ( Displaced with communited or segmental) fracture occurred in 6 patients. All the 40 patients were operated, within 14 days of admission to our department . 36 ( $90 \%$ ) out of 40 were operated within 7 days and rest 4 patients in next 7 day ( 14 days from the day of admission ).Length and type of plate was determined according to extent of communition of fracture. Aim was to put 3 screws in medial and 3 screws in lateral fragments of fracture through both the cortices. 7 hole plate was used in $24(60 \%)$ patients , 8 hole in $8(20 \%)$ patients and 9 hole in $8(20 \%)$ patients. Screw sizes used were between 14 to $20 \mathrm{~mm}$, both normal cortical and locking screws were used.Various complications are seen during the post operative and follow up period. Superficial infection is seen in $4(10 \%)$ patients in post op period and rest of the complications are seen during the follow up period i.e . hyper trophic skin scar in 6 ( $15 \%)$, plate prominence in $4(10 \%)$, delayed union in $4(10 \%)$ and plate loosening in 2 ( $5 \%)$, leading to malunion. Duration of union was $<12$ weeks in $36(90 \%)$ and $>12$ weeks in $4(10 \%)$ patients. Patients were evaluated according to 100-point scoring system of CONSTANT AND MURLEY ${ }^{13}$. Excellent score were noted in $75 \%$, good in $20 \%$, fair in $5 \%$.

\section{Discussion}

The best treatment strategy for displaced midshaft clavicle fractures still remains a topic of debate. Traditionally midshaft clavicle fractures had been treated nonoperatively. Neer ${ }^{15}$ and Rowe ${ }^{16}$ in the 1960 's recommended conservative treatment for clavicular fractures in view of very small incidence of nonunion rates in their studies $(0.1 \%$ and $0.8 \%$ respectively). No one has been able to reproduce these results so far. The recent trend is shifting towards internal fixation of these displaced midshaft clavicle fractures because of high rates of complications with conservative reatment. Three types of fixation are available for middle-third clavicle fractures : 1). intramedullary devices. 2). Plates. 3). External fixators. Intramedullary fixation can be done by smooth or threaded K- wires, Steinman pins, Knowles pins, Hagie pins, Rush pins or Cannulated screws ${ }^{17,18}$. Plate fixation can be done with a 3.5-mm dynamic compression plate (DCP), low-contact dynamic compression plates, reconstruction plates or locking compression plate with at least three screws (six cortices) in both the medial and lateral fragment each, and an interfragmentary lag screw whenever the fracture pattern needs it. Plating of acute clavicle fractures is advocated as the preferred fixation method by many authors 19 . Biomechanically, plate fixation is superior to intramedullary fixation because it better resists the bending and torsional forces that occur during elevation of the upper extremity above shoulder level ${ }^{20}$. Disadvantages of plate fixation include the necessity for increased exposure and soft-tissue stripping, increased risk of damage to the supraclavicular nerve, slightly higher infection rates, and the risk of refracture after plate removal ${ }^{21}$.

The present study was compared with Bostman et al ${ }^{22}$ and Cho et al ${ }^{23}$ study. In Bostman et al ${ }^{22}$ study, total 103 patients of middle third clavicle fractures, were treated by open reduction and internal fixation with plates and screws. In Cho et al study ${ }^{23}, 41$ patients were treated by open reduction internal fixation with plates and screws. Reconstruction plate were used in 19 and locking compression plate in 22 patients. Our study group include 30 ( $75 \%$ ) males and 10 ( $25 \%$ ) females with male : female ratio of $3: 1$. The average age of patient was $32 \mathrm{yrs}$, range being 19 - 55 years. $60 \%$ patients were in age group of $19-39 \mathrm{yrs}$. Our results match with Bostman et al ${ }^{22}$ study in which average age was 33.4 yrs, range being 19 - 62 years but slightly differs from $\mathrm{Cho}^{23}$ et al study, where average age was 45 yrs in recon group ( range $22-70$ yrs ) and 46 yrs in locking compression plate group ( range $19-69$ yrs.). This is because of upper age limit of group was high . The male: female ratio in Bostman et $\mathrm{al}^{22}$ and Cho et al ${ }^{23}$ study are 2.8 and 2.4 respectively nearly matching with our study $\mathrm{m} / \mathrm{f}$ ratio of $3: 1$. This result shows males are more involved than female because males are active, outgoing and engaged in more out door activities, thus more prone to accidents and fall but females are engaged in household activities. In our study all the patients were operated within 14 days of admission , 36 within 7 days and rest 4 in next 7 days ( 14 days from the day of admission ). In Bostman et al ${ }^{22}$ patients were operated within 3 days and in Cho et al ${ }^{23}$ study within 4 to 9 days (in recon group 4 days and lcp group 9 days). This deviation in result is because of fixed OT days assigned to us. Fractures were classified as per Robinson's classification. We have, 34 ( $85 \%$ ) patients of Type 2 B-1 and 6 ( $15 \%$ ) Type -2 B-2. This finding was similar to Bostman et al ${ }^{22}$ series, but differ from Cho et al ${ }^{23}$ study, where 25 ( $61 \%$ ) patients belong to Robinson Type 2 B-2 and 16 ( $39 \%$ ) to Type 2 B-1. In our study group union occurs in all patients but time period varies. Duration of union was $<12$ weeks in $36(90 \%)$ and $>12$ weeks in $4(10 \%)$ patients , due to presence of communition at the fracture site which united at 16 weeks post op. The results was consistent with Cho et al ${ }^{23}$ and Lazarus MD ${ }^{24}$ study, where union time was between 13.2 to 14.6 weeks and between 6 to 12 weeks respectively. Like every other procedure, we faced various complications during the post operative and follow up period. Superficial infection in $4(10 \%)$, hyper trophic skin scar in 6 ( $15 \%)$, plate prominence in $4(10 \%)$, delayed union in $4(10 \%)$ and plate loosening in $2(5 \%)$ by the end of 6 weeks , leading to malunion. Plate loosening occured because of poor compliance with post operative protocol. Patient went for farming in field and lifts heavy weight with loosen implant in situ, leading to malpositioning of 
fracture fragments . The results of plate loosening in Bostman et al ${ }^{22}$ and Cho ${ }^{23}$ et al study are $6.80 \%$ and 7.31 $\%$ respectively, which is similar to our study group. The over all complication rate in Bostman et al ${ }^{22}$ was $23 \%$, similar to our study results of $25 \%$, with over lap of complications among the patients.

\section{Conclusion}

Traditional (non-operative / conservative ) method of managing middle third clavicle fractures leads to high complication rates i.e: shoulder pain, shoulder weakness, residual pain ${ }^{10}$, symptomatic malunion, and poor functional outcome with cosmetic deformity ${ }^{3}$. Operative method with plating using six cortical purchase on either side of fractures gives stable construct, predictable union and optimal functional outcome. Use of Interfragmentary screw provide more stable fixation when used judiciously. Despite limitations of our study in terms of lack of control group and small sample size, we encourage plating as a one of the rational method of fixation of clavicle fractures. Stable fixation in middle third clavicle fractures performed carefully is safe and effective treatment method to give immediate pain relief, prevention of development of shoulder stiffness and restoration of normal shoulder function with minimal complications.

\section{Bibliography}

[1]. Michael D. McKee. Clavicle Fractures. In: Bucholz, Robert W. ; Heckman, James D. ; Court-Brown, Charles M. ; Tornetta, Paul eds . Rockwood And Green's Fractures In Adults, 7th Edition.

[2]. Philadelphia ; Lippincott Williams \& Wilkins. 2010. pg 1106.

[3]. Rowe CR. An atlas of anatomy and treatment of mid-clavicular fractures. Clin Orthop .1968;58: $29-42$.

[4]. Partha Saha, Prasenjit Datta, Saankritya Ayan, Anant Kumar Garg, Utpal Bandyopadhyay, and Srikanta Kundu . Plate versus titanium elastic nail in treatment of displaced midshaft clavicle fractures. Indian J Orthop. 2014 . Nov-Dec; 48(6): 587-593.

[5]. Seo GS, Aoki J, Karakida O, et al. Case report: nonunion of a medical clavicular fracture following radical neck dissection: MRI diagnosis. Orthopedics 1999;22:985-986.

[6]. . Throckmorton T, Kuhn JE. Fractures of the medial end of the clavicle. J Shoulder Elbow Surg 2007;16:49-54.

[7]. Robinson CM. Fractures of the clavicle in the adult. J Bone Joint Surg Br 1998;80B: 476-484.

[8]. Stanley D, Trowbridge EA, Norris SH. The mechanism of clavicular fracture. A clinical and biochemical analysis. J Bone Joint Surg Br 1988;70B:461-464.

[9]. Hill JM, McGuire MH, Crosby LA. Closed treatment of displaced middle-third fractures of the clavicle gives poor results. J Bone Joint Surg Br 1997;79B:537-539.

[10]. Zlowodzki M, Zelle BA, Cole PA, et al. Treatment of midshaft clavicle fractures: systemic review of 2144 fractures. J Orthop Trauma 2005;19:504-507.

[11]. . McGuire MH, Crosby LA. Closed treatment of displaced middle-third fractures of the clavicle gives poor results. J Bone Joint Surg Br. 1997;79:537-539. doi: 10.1302/0301-620X.79B4.7529. [PubMed][Cross Ref].

[12]. Jamal E. H. Assobhi. Reconstruction plate versus minimal invasive retrograde titanium elastic nail fixation for displaced midclavicular fractures.J Orthop Traumatol. Dec 2011; 12(4): 185-192.

[13]. Chin-En Chen, $\bigotimes$ Rei-Jahn Juhn, and Jih-Yang Ko. Anterior-inferior plating of middle-third fractures of the clavicle. Arch Orthop Trauma Surg. Apr 2010; 130(4): 507-511.

[14]. Constant CR, Murley AG, A clinical method of functional assessment of shoulder. Clin Orthop Relat Res. 1987;214: 160- 164

[15]. Jeffrey EB, Robert PN ,Eric JG. Debridmentof partial thickness tears of rotator cuff without acromioplasty, long term followup and review of literature. J BoSne Joint Surg. 1998;80:733-748

[16]. Neer CS ., 2nd Nonunion of clavicle. J Am Med Assoc. 1960;172:1006 -11

[17]. Rowe CR . An atlas of anatomy and treatment of mid clavicular fractueres. Clin Orthop Relat Res. 1968;58:29-42

[18]. Keley RF, Schmidt AH. Open reduction and internal fixation of fractures and non unions. In : Thompson R C,editor. The Shoulder.New York :Raven Press ;1995. P 183

[19]. Neviaser RJ,Neviaser JS,Neviaser TJ. A simple technique for internal fixation of clavicle . a long term evaluation. Clin Orthop. 1975;109:103 . doi:10.1097/00003086-197506000-00013

[20]. Ngarmukos C, Parkpain V, Patradul A.Fixation of fractures of midshaft of clavicle with kirschner wires results in 108 patients. J Bone Joint Surg. 1998; 80B:106. doi:10.1302/0301-620X.80B1.7880

[21]. Mullaji AB, Jupiter JB. Low contact dynamic compression plating of clavicle. Injury. 1994; 25: 41. doi:10.1016/00201383(94)90183-X

[22]. Canadian Orthopaedic Trauma Society. Non Operative treatment compared with plate fixation of displaced midshaft clavicular fractures. A multicentric, randomized clinical trail. J Bone Joint Surgery Am. $2007 ; 89: 1-10$

[23]. Bostman O, Manninen M, Philajamaki H. Complications of plate fixation in fresh displaced mid clavicular fractures. J Trauma , 1997; 43:778-783

[24]. Chul-Hyun Cho, MD , Kwang- Soon Song, MD, Byung - Woo Min, MD ,Ki - Cheor Bae, MD , Kyung - Jae Lee , MD . Reconstruction Plate versus Reconstruction Locking Compression Plate For Clavicular Fractures . Clinics in Orthopaedic Surgery $2010: 2: 154-159$

[25]. Lazarus MD. Fractures Of The Clavicle. Bucholz RW , Heckman JD. Rockwood And Green's Fractures In Adults, 5th Edition. Philadelphia .Lippincott Williams \& Wilkins. 2001 . Pg 1041 -1078 . 
Case Clinical Photograph

Different movements of shoulder joint

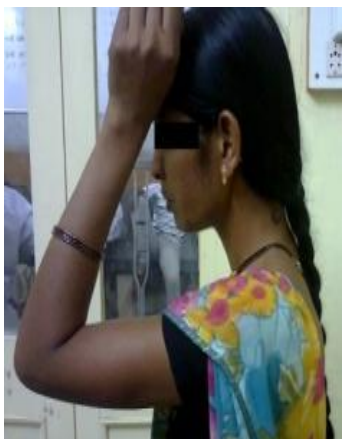

Flexion

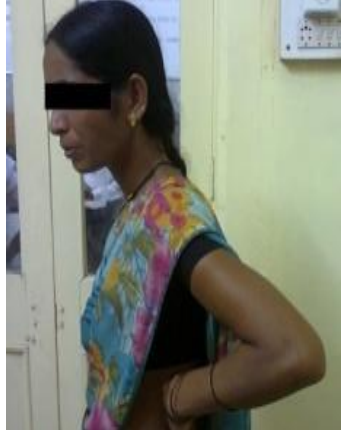

Extension

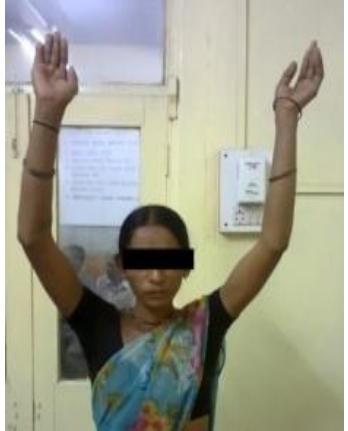

Overhead Abduction
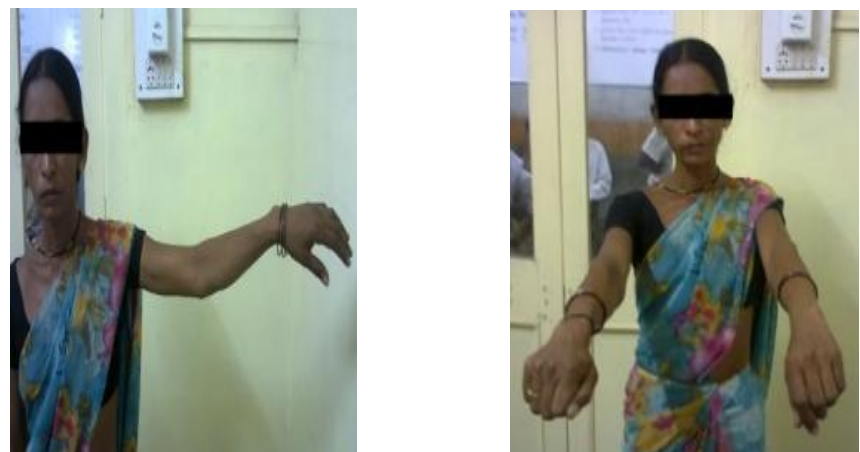

Case X - Ray

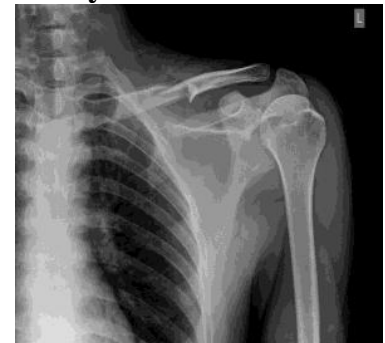

Pre -Operative

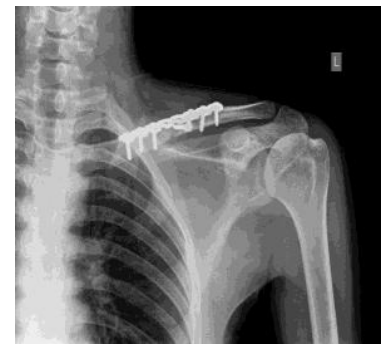

6 -Months Post - Op

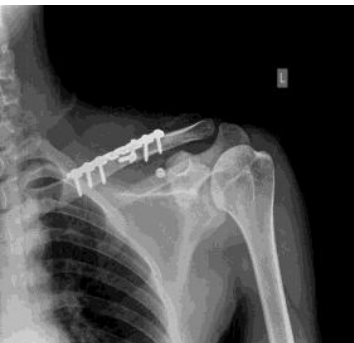

Immediate Post -Op

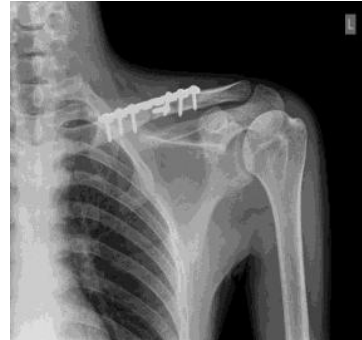

3 Months Post - Op

Complications Photograph.

Hypertrophic Skin Scar

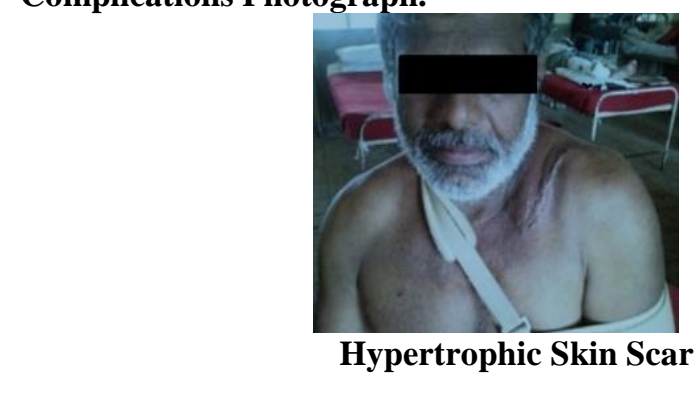

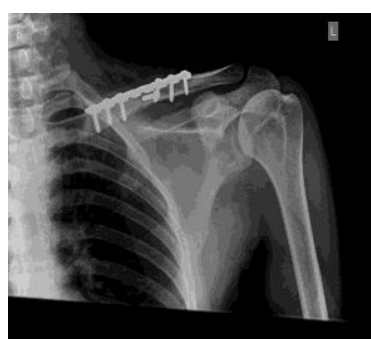

12 Months Post - Op

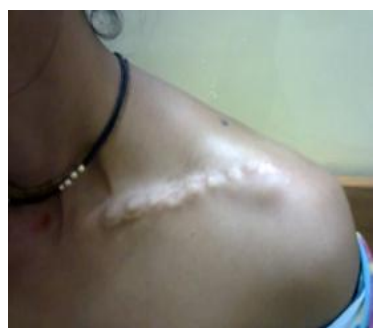

Plate Prominence 